posing that a compound thus constituted could not exist. Chromous chloride is one of the most energetic deoxidizing agents known, and we can bardly conceive it to be united in a stable compound with a substance which so readily parts with its oxygen as chromium tri-oxide. Hence I am disposed to regard the constitution of the salts of Péligot as very different from that implied by the above method of representation: indeed, to the best of my know. ledge, the general formula assigned to these salts expresses not a single experimental fact, unless it be the mode of their decomposition by water, probably it had reference to the views of Rose and Berzelius respecting the constitution of the so-called chlorochromic acid. The following structural formulæ better represent in my opinion the constitution of these compounds and their relation to chromyl dichloride.

Magnesium Chlorochromate.

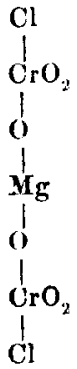

Chromium Chlorochromate.

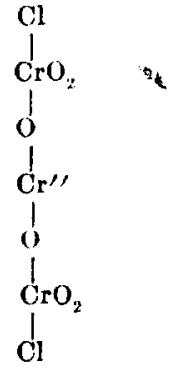

These substances may also be thus represented :-

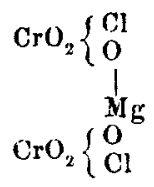<smiles>COC(=O)COC(=O)OC</smiles>

The relation of the new oxychloride to chromyl dichloride is thus very apparent. Three molecules of chromyl dichloride when heated are resolved into one molecule of chromium chlorochromate and four atoms of chlorine.

\title{
ON NONTRONITE.
}

\author{
By T. E. Thurpe, Ph. D.
}

(From the Proceedings Lit. and Phil. Society of Manchester, Vol. IX., No. 1.)

THERE exists some doubt among mineralogists as to whether Nontronite is to be regarded as a distinct mineral species. Owing to the difficulty of obtaining it in a fit state for investigation, the few analyses hitherto published by Berthier, Dufrénoy, Jacquelin 
and others have taught us but little concerning its true nature. The following analysis made on a comparatively pure specimen may throw additional light on the constitution of this compound. The sample analyzed was discovered unclassified in the mineralogical cabinet at Heidelberg, and was stated by Professor Blum, who was disposed to regard it as Pinguite, to have been found in the neighborhood of Heppenheim in the Bergstrasse.

$1.4155 \mathrm{grm}$. of the substance was heated with fuming hydrochloric acid until the mineral appeared to be completely decomposed; the solution was evaporated to complete dryness, and the separation of the silica effected in the usual manner.

Silica obtained, $0.5680 \mathrm{grm}$.

The weighed silica was then dissolved in caustic potash and proved to be entirely free from sand or quartz.

To the filtrate from the silica were added a few drops of nitric ncid, the solution was boiled and the iron precipitated by ammonia.

Ferric oxide, 0.5757 grm.

The weighed precipitate was next dissolved in strong hydro. chloric acid, water added, and the solution filtered from a minute quantity of silica which had escaped separation by the previous evaporation.

Silica (not completely separated), $0.0030 \mathrm{grm}$.

Caustic soda was then added in slight excess to the filtrate, and the ferric oxide again precipitated, washed, ignited and weighed. The re-precipitated ferric oxide weighed $0.5740 \mathrm{grm}$. Hence the substance was free from any appreciable quantity of alumina.

To the ammoniacal filtrate a few drops of ammonium oxalate were added, and the precipitate was ignited and determined as caustic lime.

$$
\text { Lime, } 0.0380 \mathrm{grm} \text {. }
$$

On adding sodium phosphate to the filtrate a mere trace of magnesia, appearing only after the lapse of some hours was found.

The remaining constituent, namely, water, was determined by igniting the mineral in a stream of dry carbonic acid carefully freed from air, until the loss of weight appeared constant.

\section{$1.1205 \mathrm{grm}$. substance lost 0.2311 grm. water.}

Calculated from the foregoing analysis, the composition of the mineral is as follows:-

Lime

Magnesia

Ferric oxide

Silica......

Water 
On subtracting the lime, which evidently may be regarded as an unessential constituent, the percentage composition agrees very well with that required by the formula-

$$
\mathrm{Fe}_{2} \mathrm{O}_{3} 3 \mathrm{SiO}_{2}+5 \mathrm{H}_{2} \mathrm{O} \text {. }
$$

Found.

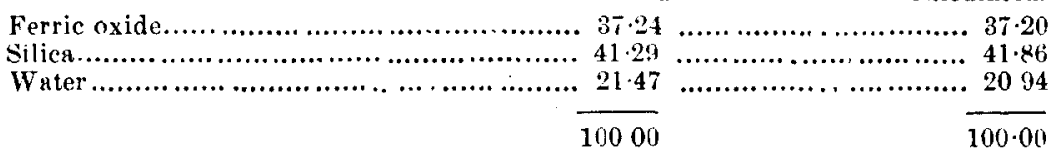

Nontronite is evidently a product of the decomposition by weathering of some siliceous mineral rich in iron. It possesses a light green color, whicb, on the expulsion of water, changes to a dark chestnut brown. It is perfectly opaque, and shows no evidence of crystallization. Its fracture is uneven, and the lustre of its streak resinous. It is unctuous to the touch, yields easily to the nail, and is somewhat harder than talc.

The following analysis by Biewend, made upon a specimen found at Andreasberg, agrees remarkably well with the foregoing determinations:

Ferric oxide ................................................................... $37 \cdot 30$

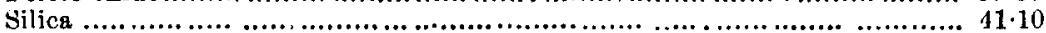

Water....................................................................... 21.56

$\overline{99 \cdot 96}$

\title{
ON THE NEW CHEMICAL NOMENCLATURE.
}

\author{
By Dr. Adolph OTt.
}

(Continued from page 53.)

ADVANCED chemists have foreseen the difficulties to be encountered in applying old and familiar names to the new notation, and several authors of recent works have given the terminals ous and $i c$ to names of metals to indicate their combinations with electro. negative elements. Yet, this system of names does not give any idea of the actual composition of the body so named. The London Chemical News of November 26, 1869, in a favorable review of Dr. Odling's "Outlines of Chemistry," says: "As a consequence of this method it happens that bodies differently constituted have similarly constructed; names; thus $\mathrm{Cu} \mathrm{O}, \mathrm{Fe}_{2} \mathrm{O}_{3}$ and $\mathrm{Sn} \mathrm{O}_{2}$ are cupric, ferric and stannic oxides, respectively." And we may here add to this frank confession that similar names applied to combinations of metals with the monatomic halogens produce still greater confusion. These difficulties are entirely obviated in the new

Vol. LX.-Thikd SERIES.-No, 2-A Uavst, 1870. 